\title{
Effect of high dose growth hormone with glutamine and no change in diet on intestinal absorption in short bowel patients: a randomised, double blind, crossover, placebo controlled study
}

\author{
J Szkudlarek, P B Jeppesen, P B Mortensen
}

\begin{abstract}
Background-High dose growth hormone, glutamine, and a high carbohydrate diet may improve intestinal function in short bowel patients.

Aims-To investigate if growth hormone with glutamine and no change in diet improved intestinal function.

Patients and methods-Eight short bowel patients were randomised in a double blind crossover study between placebo and growth hormone (mean $0.12 \mathrm{mg} / \mathrm{kg} /$ day) with oral (mean $28 \mathrm{~g} /$ day) and parenteral glutamine (mean 5.2 g/day) for 28 days. Balance studies were performed at baseline and five days after placebo and treatment were terminated. Dietary energy, carbohydrate, and fat were maintained as usual.

Results-Growth hormone with glutamine did not improve intestinal absorption of energy (baseline, placebo, treatment, mean: $46 \%, 48 \%, 46 \%$ of oral intake, respectively), carbohydrate $(71 \%$, $70 \%, 71 \%)$, fat $(20 \%, 15 \%, 18 \%)$, nitrogen $(27 \%, 18 \%, 19 \%)$, wet weight $(37 \%, 39 \%$, $31 \%)$, sodium $(-16 \%,-16 \%,-36 \%)$, potassium $(43 \%, 47 \%, 33 \%)$, calcium $(-16 \%$, $-16 \%,-15 \%)$ or magnesium $(-3 \%, 4 \%$, $2 \%)$ compared with placebo or baseline $(p>0.05)$ five days after treatment was terminated. All patients experienced adverse effects.

Conclusions-Combined high dose growth hormone and glutamine administered for four weeks did not improve intestinal absorption five days after treatment was terminated in short bowel patients on their usual diet.

(Gut 2000;47:199-205)
\end{abstract}

Department of
Medicine, Section of Gastroenterology

CA-2121,

Rigshospitalet,

University of

Copenhagen,

Blegdamsvej 9,

DK-2100 Copenhagen,

Denmark

J Szkudlarek

P B Jeppesen

P B Mortensen

Correspondence to:

Dr P B Mortensen. Email:

broebech@rh.dk

Accepted for publication 8 February 2000

Growth hormone has been shown to increase intestinal growth and promote adaptation in animal models. ${ }^{1}$ Glutamine is an important nutrient for enterocytes and is associated with maintenance of mucosal integrity and intestinal adaptation in animals. ${ }^{2}$ High carbohydrate diets improve absorption of energy in short bowel patients with a colon in continuity. ${ }^{3}$ Byrne et al combined these three modalities and found that a high dose of growth hormone
(0.14 $\mathrm{mg} / \mathrm{kg} /$ day), intravenous or oral glutamine, and a high carbohydrate/low fat diet increased nutrient and fluid absorption at the end of 3-4 weeks of treatment. ${ }^{45}$ Nearly half of their patients were able to discontinue parenteral nutrition at follow up one year later and recently they have reported that a major treatment effect was observed in more than 200 short bowel patients from their institution. ${ }^{6}$ Although the studies were not controlled it is hard to disregard the impressive results from centres who treat short bowel patients on long term parenteral nutrition. The question is whether the effect is caused exclusively by the increase in the dietary carbohydrate:fat ratio and to what extent the addition of growth hormone and glutamine further improves intestinal absorption. Scolapio and colleagues ${ }^{7}$ evaluated the effect of high dose growth hormone and glutamine in eight patients who were treated continuously with a high carbohydrate diet in a controlled and randomised study and found no alterations in assimilation of macronutrients, stool volumes, or morphometry of the small bowel mucosa. They found a modest increase in sodium and potassium absorption and a transient increase in body weight.

The aims of our study were to assess the same treatment in a double blind, placebo controlled, crossover trial in patients with short bowel syndrome who continued on their usual diet. A baseline pre-study period was introduced to avoid a treatment effect in comparison with placebo as a result of possible carryover effects. Intestinal function was measured five days after treatment was terminated because acute and transient effects of the treatment lasting less than five days were considered to be of little clinical importance. Only steady state short bowel patients on home parenteral nutrition (HPN) who had been treated at our institution for at least a year were included to avoid coincidence between adaptive improvements in the early phase after admission to a specialised unit and the specific effects of growth hormone and glutamine.

\section{Methods}

PATIENTS

Eight patients (seven women and one man) with short bowel syndrome who had been dependent on HPN for an average of 7 years

Abbreviations used in this paper: $\mathrm{HPN}$, home parenteral nutrition; IGF-1, insulin-like growth factor 1 . 
(range 3-11 years) completed the randomised study (table 1). Mean residual small bowel length was $104 \mathrm{~cm}$ (range 30-150), measured peroperatively and described in operative reports. Four patients had part of the colon in continuity. The ileocaecal valve was resected in all patients. Six patients had Crohn's disease and two had suffered mesenteric infarction caused by arterial thrombosis or volvulus. Patients with Crohn's disease had been in remission for more than six months and had not received steroids for a similar period of time. Assessments were based on a clinical evaluation and laboratory data. Remission was not assessed by endoscopy or $x$ ray examination. Within one year before entrance, a clinical indication for one of these procedures was found in one patient only, who showed no evidence of recurrence. A mean of 7 years (range 1-11 years) had elapsed since the last surgery. Patients had received continuity of care at our institution for at least one year.

Patients with a history of malignancy, diabetes mellitus, or hepatic, renal, or cardiac failure were excluded, as were those with pseudo obstruction. All patients were capable of oral food intake but were unable to maintain adequate nutrition, hydration, or both, without HPN. Trace elements (serum calcium (ionised), phosphate, magnesium, and zinc) were normal and not significantly changed during the study. Fatty acids were measured in the plasma phospholipid fraction. Traditionally, the definition of essential fatty acid deficiency has relied on the biochemical detection of a 20:3n-9/20:4n-6 ratio (Holman index) of more than 0.2 . One patient (No 5) had a Holman index of 0.7 while this index was below 0.09 in the remainder, indicating that the remaining seven had no deficiency in essential fatty acids. Patient No 5 did not receive intravenous fat (Intralipid R) or fat soluble vitamins (Vitalipid R) which were administered to the other seven patients. Vitamin A (plasma retinol) levels were less than the $95 \%$ limit $(0.52 \mu \mathrm{g} / \mathrm{ml})$ in one patient (No 1, $0.26 \mu \mathrm{g} / \mathrm{ml}$ ). Vitamin E was measured as plasma $\alpha$ and $\gamma$ tocopherols. Plasma $\alpha$ tocopherol was below the lower 95\% limit of healthy controls $(4.25 \mu \mathrm{g} / \mathrm{ml})$ in five patients (Nos 1, 2, 4, 5, and 7; range 2.2-3.6 $\mu \mathrm{g} / \mathrm{ml}$ ) and plasma $\gamma$ tocopherol was below the $95 \%$ limit $(0.28 \mu \mathrm{g} / \mathrm{ml})$ in one patient (No. 4, $0.05 \mu \mathrm{g} / \mathrm{ml})$. Vitamin D was not measured.

The protocol was approved by the Ethics Committee for Medical Research in Copenhagen, Denmark. Procedures were in accordance with the ethical standards of the Helsinki Declaration of 1975 , as revised in 1983. All participants gave informed consent before beginning the study.

\section{STUDY DESIGN}

This was a double blind, placebo controlled, randomised, crossover study. On inclusion in the study, patients were allocated randomly in a double blind manner to initial treatment with placebo (four patients) or active treatment (the remaining four patients). Patients were randomised in blocks of four. A total of nine patients were studied but one patient was excluded shortly after entering the study because of intestinal obstruction treated by surgery. She received placebo treatment and was never treated with growth hormone and glutamine.

Active treatment consisted of subcutaneous recombinant human growth hormone $(0.14 \mathrm{mg} / \mathrm{kg} /$ day; Norditropin, Novo-Nordisk AS, Bagsværd, Denmark) divided into two daily injections, oral L-glutamine (30 g/day; Ajinomoto, Kawasaki City, Japan) divided into six doses dissolved in a beverage of the patient's choice, and parenteral glutamine as glutamine enriched infusions $(17 \%$ of nitrogen as glutamine; Glavamin, Pharmacia-Upjohn, Sweden) which matched the patients' usual parenteral intake of amino acid nitrogen (that is, other amino acids were reduced slightly to maintain constant overall parenteral administration of nitrogen). Placebo treatment consisted of subcutaneous injections of saline serving as a control for growth hormone, L-alanine powder $30 \mathrm{~g} / \mathrm{d}$ in six daily doses as a control for oral glutamine, and the patient's usual parenteral programme as a control for the glutamine enriched solutions. Each treatment period lasted 28 days. Duration of treatment and doses of growth hormone and glutamine were as recommended in the earlier uncontrolled studies of Byrne et al.

Patients were admitted to our department on three occasions for balance studies: prior to the start of treatment (baseline) and five days after completion of each treatment period (active treatment or placebo). It was arbitrarily decided to measure the effect of treatment five days after its termination because a sustained rather than an acute effect was considered to be imperative for the clinical use of this therapy, as continuous long term treatment (months or years) with high dose growth hormone is unrealistic. After completion of the second

Table 1 Patient characteristics and doses of growth hormone and glutamine

\begin{tabular}{|c|c|c|c|c|c|c|c|c|c|c|}
\hline $\begin{array}{l}\text { Patient } \\
\text { No }\end{array}$ & Age (y) & Sex & $\begin{array}{l}\text { Duration of } \\
\operatorname{HPN}(y)\end{array}$ & $\begin{array}{l}\text { Small bowel } \\
(\mathrm{cm})\end{array}$ & $\begin{array}{l}\text { Colon } \\
(\%)^{*}\end{array}$ & $\begin{array}{l}B M I \\
\left(\mathrm{~kg} / \mathrm{cm}^{2}\right)\end{array}$ & Diagnosis & $\begin{array}{l}\text { Growth hormone } \\
\text { (mg//kg/day) }\end{array}$ & $\begin{array}{l}\text { Oral glutamine } \\
\text { (g/day) }\end{array}$ & $\begin{array}{l}\text { Parenteral } \\
\text { glutamine } \\
\text { (g/day) }\end{array}$ \\
\hline 1 & 33 & $\mathrm{~F}$ & 11 & 100 & 86 & 22 & CD & 0.14 & 30 & 3.2 \\
\hline 2 & 74 & $M$ & 7 & 90 & 86 & 24 & MI & 0.09 & 29 & 4.1 \\
\hline 3 & 42 & $\mathrm{~F}$ & 5 & 100 & 43 & 19 & $\mathrm{CD}$ & 0.14 & 30 & 3.4 \\
\hline 4 & 45 & $\mathrm{~F}$ & 10 & 140 & 28 & 24 & $\mathrm{CD}$ & 0.07 & 30 & 4.0 \\
\hline 5 & 47 & $\mathrm{~F}$ & 11 & 150 & 0 & 25 & $\mathrm{CD}$ & 0.05 & 19 & 3.7 \\
\hline 6 & 32 & $\mathrm{~F}$ & 3 & 120 & 0 & 21 & CD & 0.14 & 29 & 8.5 \\
\hline 7 & 49 & $\mathrm{~F}$ & 8 & 100 & 0 & 24 & $\mathrm{CD}$ & 0.12 & 29 & 6.8 \\
\hline 8 & 55 & $\mathrm{~F}$ & 3 & 30 & 0 & 21 & MI & 0.14 & 30 & 8.0 \\
\hline
\end{tabular}

M, male; F, female; BMI, body mass index; $\mathrm{CD}$, Crohn's disease; MI, mesenteric infarction.

${ }^{\star}$ Per cent of remnant colon. ${ }^{8}$ 
balance study, patients were crossed over to the other treatment for another 28 days. There was no washout period between active treatment and placebo but in patients who were randomised to start on active treatment, 33 $(28+5)$ days had elapsed between the end of active treatment until the placebo treatment was evaluated.

Patients were requested to complete a record of their usual consumption of food and beverages over a three day period, 2-3 weeks before the first admission. They were told to select a period representative of their common eating and drinking habits, to weigh food components on a kitchen balance, and to measure all liquids to the nearest $100 \mathrm{ml}$. The wet weight of the diet was calculated as the total weight of food and beverages, and ostomy output was calculated as the wet weight of faeces: absorption of wet weight was calculated as the difference between these two values. Consumption of energy and major food components was calculated using the DANKOST computer program. ${ }^{9}$ At each stay in hospital, patients received a fixed diet with a known and constant amount of energy and macronutrients to meet their usual needs, as indicated from the questionnaire and interview with the dietician at admission. Non-energy containing liquids were provided ad libitum but patients completed a record of consumption and were asked to keep the daily intake of liquids as constant as possible during the three study periods. Patients received their usual parenteral nutrition and medications unless otherwise noted and continued their usual antimotility and antisecretory agents in unchanged doses. Five patients had been receiving antimotility agents (codeine, opium, Retardine R, loperamide) for 11 months to more than 10 years. One patient had received octreotide for 31 months, and four had received proton pump inhibitors for 3-39 months prior to entrance. One patients had been treated with morphine for 10 years and methadone for 11 months.

Each of the three study periods began on the morning of the first day of admission. The first day (day 1) was used as a run in period. Starting on the following morning, stools and urine were collected for three days (days 2-4). The diet was fixed for days $1-4$, and was prepared in duplicate on the last day of sampling for laboratory analysis. Stools and diets were analysed for energy (bomb calorimetry), fat, carbohydrates, nitrogen, sodium, potassium, calcium, and magnesium as described previously. ${ }^{3} 10$ Intestinal absorption was calculated as the dif- ference between oral intake and faecal loss. After absorption studies had been completed, patients started placebo or active treatment (day 5). They were instructed to selfadminister subcutaneous injections and were discharged after 3-4 days (days 7-8). At home, patients consumed their usual diets. Close contact with patients was maintained to ensure compliance and to detect and treat adverse effects. Blood was obtained weekly for measurement of serum insulin-like growth factor 1 (IGF-1), electrolytes, and blood glucose, and for renal and liver tests. Patients kept a diary of treatment. Vials and packages were returned and counted at the end of the study to assess compliance.

STATISTICAL ANALYSIS

A paired Student's $t$ test was used for statistical analysis after the data were plotted to ensure that there was no significant carryover or sequence effect. Data are expressed as mean (SEM).

\section{Results}

Patient characteristics and doses of growth hormone administered (mean $0.12 \mathrm{mg} / \mathrm{kg} /$ day), oral glutamine (mean $28 \mathrm{~g}$ /day), and parenteral glutamine (mean $5.2 \mathrm{~g} /$ day) are shown in table 1. Parenteral supplements and oral intake of energy, wet weight, and sodium at baseline in individual patients are shown in table 2. Oral energy intake was 7.1-14.0 MJ/day, with an energy ratio from carbohydrates of $30-55 \%$.

INTESTINAL ABSORPTION OF ENERGY, FAT, CARBOHYDRATES, AND NITROGEN

Energy was measured by two different methods: bomb calorimetry or by summarising the energy values of carbohydrates, fat, and proteins (calculated on the assumption that all nitrogen originated from protein) (table 3 ). Treatment with combined growth hormone and glutamine did not change intestinal absorption of energy or macronutrients compared with baseline values or placebo treatment. Absorption of energy was 4.5 of 10.2 $\mathrm{MJ} /$ day $(46 \%)$ at baseline, 4.7 of $10.1 \mathrm{MJ} /$ day (48\%) after placebo, and 4.4 of $10.0 \mathrm{MJ} /$ day $(46 \%)$ after active treatment. Absorption of fat was 12 of $64 \mathrm{~g} /$ day $(20 \%)$ at baseline, 8 of $66 \mathrm{~g} /$ day $(15 \%)$ after placebo, and 10 of 68 $\mathrm{g} /$ day $(18 \%)$ after active treatment. Absorption of carbohydrates was 208 of $292 \mathrm{~g} /$ day $(71 \%)$ at baseline, 205 of $287 \mathrm{~g} /$ day (70\%) after placebo, and 203 of $286 \mathrm{~g} /$ day (71\%) after active treatment. Absorption of nitrogen was 4.0 of 14.2

Table 2 Parenteral supplements and oral intake of energy, wet weight, and sodium

\begin{tabular}{|c|c|c|c|c|c|c|c|}
\hline \multirow[b]{2}{*}{ Patient No } & \multicolumn{3}{|c|}{ Parenteral supplements } & \multicolumn{4}{|l|}{ Oral intake } \\
\hline & $\begin{array}{l}\text { Energy } \\
\text { (Mf/day) }\end{array}$ & $\begin{array}{l}\text { Wet weight } \\
\text { (kg/day) }\end{array}$ & $\begin{array}{l}\text { Sodium } \\
\text { (mmol/day) }\end{array}$ & $\begin{array}{l}\text { Energy } \\
\text { (MFlday) }\end{array}$ & $\begin{array}{l}\text { Carbohydrates } \\
\text { (\% of energy) }\end{array}$ & $\begin{array}{l}\text { Wet weight } \\
\text { (kg/day) }\end{array}$ & $\begin{array}{l}\text { Sodium } \\
\text { (mmol/day) }\end{array}$ \\
\hline 1 & 2.3 & 2.0 & 153 & 10.6 & 55 & 3.0 & 176 \\
\hline 2 & 6.8 & 2.2 & 100 & 9.2 & 52 & 4.0 & 151 \\
\hline 3 & 1.5 & 0.8 & 38 & 7.1 & 45 & 4.4 & 236 \\
\hline 4 & 4.1 & 2.2 & 169 & 7.1 & 52 & 3.4 & 123 \\
\hline 5 & 3.3 & 3.5 & 279 & 14.0 & 30 & 4.7 & 190 \\
\hline 6 & 8.2 & 3.2 & 100 & 7.8 & 51 & 3.0 & 105 \\
\hline 7 & 1.5 & 1.7 & 136 & 9.0 & 45 & 4.2 & 171 \\
\hline 8 & 5.9 & 3.2 & 221 & 8.7 & 39 & 2.8 & 130 \\
\hline
\end{tabular}


Table 3 Intestinal absorption of energy, fat, carbohydrates, and nitrogen at baseline and five days after 28 days of treatment with placebo or growth hormone in combination with glutamine (mean (SEM); $n=8$ )

\begin{tabular}{|c|c|c|c|c|c|c|c|c|}
\hline & \multicolumn{2}{|c|}{ Baseline } & \multicolumn{2}{|c|}{ Placebo } & \multicolumn{2}{|c|}{ Treatment } & \multicolumn{2}{|c|}{ Effect ${ }^{*}$} \\
\hline \multicolumn{9}{|c|}{ Energy (MJ/day) (bomb calorimetry) } \\
\hline Diet & 10.2 ( & $(1.0)$ & 10. & $(1.0)$ & 10. & $(0.9)$ & -0.1 & $(0.2)$ \\
\hline Faeces & & $(0.9)$ & & $(0.9)$ & & $(0.9)$ & 0.2 & $(0.2)$ \\
\hline Absorption & & $(0.6)$ & & $(0.5)$ & & $(0.4)$ & -0.3 & $(0.3)$ \\
\hline Absorption (\%) & 46 & (6) & 48 & (5) & 46 & (5) & -2 & (2) \\
\hline \multicolumn{9}{|c|}{ Energy $(\mathrm{MJ} /$ day) (sum of fat + carbohydrates + protein) $\dagger$} \\
\hline Diet & & $(1.0)$ & & $(1.0)$ & & $(1.0)$ & & $(0.3)$ \\
\hline Faeces & & $(0.7)$ & & $(0.9)$ & & $(0.8)$ & 0.1 & $(0.2)$ \\
\hline Absorption & & $(0.7)$ & & $(0.6)$ & & $(0.5)$ & 0.1 & $(0.4)$ \\
\hline Absorption (\%) & 48 & (6) & 46 & (6) & 46 & (6) & 0 & (3) \\
\hline \multicolumn{9}{|l|}{ Fat (g/day) } \\
\hline Diet & 64 & (9) & 66 & $(10)$ & 68 & (11) & 2 & (3) \\
\hline Faeces & 53 & (9) & 59 & (11) & 58 & (11) & -1 & (3) \\
\hline Absorption & 12 & (6) & 8 & (3) & 10 & (2) & 3 & (4) \\
\hline Absorption (\%) & 20 & (8) & 15 & (6) & 18 & (5) & 3 & (4) \\
\hline \multicolumn{9}{|c|}{ Carbohydrates (g/day) } \\
\hline Diet & 292 & (37) & 287 & (32) & 286 & (32) & -1 & (11) \\
\hline Faeces & 84 & (16) & 82 & (19) & 83 & (16) & 1 & (5) \\
\hline Absorption & 208 & (30) & 205 & (30) & 203 & (24) & -1 & (16) \\
\hline Absorption (\%) & 71 & (5) & 70 & (7) & 71 & (5) & 1 & (3) \\
\hline \multicolumn{9}{|l|}{ Nitrogen (g/day) } \\
\hline Diet & \multicolumn{2}{|c|}{$14.2(1.0)$} & \multicolumn{2}{|c|}{$12.3(1.2)$} & \multicolumn{2}{|c|}{$13.4(1.0)$} & \multicolumn{2}{|c|}{$1.1(0.9)$} \\
\hline Faeces & \multicolumn{2}{|c|}{$10.2(1.4)$} & \multicolumn{2}{|c|}{$9.7(1.1)$} & \multicolumn{2}{|c|}{$10.6(1.2)$} & \\
\hline Absorption & \multicolumn{2}{|c|}{$4.0(13)$} & \multicolumn{2}{|c|}{$2.6(1.2)$} & \multicolumn{2}{|c|}{$3.6(13)$} & \multicolumn{2}{|c|}{$0.2(0.8)$} \\
\hline Absorption (\%) & 27 & (9) & 18 & (13) & 19 & (10) & 1 & $(8)$ \\
\hline
\end{tabular}

$\star$ Effect is treatment compared with placebo; paired $t$ test, all non significant, $\mathrm{p}>0.05$.

†Total energy value of fat, carbohydrates, and protein (protein is calculated from nitrogen).

Table 4 Intestinal absorption of wet weight, sodium, potassium, calcium, and magnesium at baseline and five days after 28 days of treatment with placebo or growth hormone in combination with glutamine (mean (SEM); $n=8$ )

\begin{tabular}{|c|c|c|c|c|c|c|c|c|}
\hline \multirow[b]{2}{*}{ Wet weight $(\mathrm{kg} /$ day $)$} & \multicolumn{2}{|c|}{ Baseline } & \multicolumn{2}{|c|}{ Placebo } & \multicolumn{2}{|c|}{ Treatment } & \multicolumn{2}{|c|}{ Effect * } \\
\hline & \multirow{2}{*}{\multicolumn{2}{|c|}{$3.7(0.3)$}} & \multirow{2}{*}{\multicolumn{2}{|c|}{$3.7(0.2)$}} & & & & \\
\hline Diet & & & & & \multicolumn{2}{|c|}{$3.7(0.3)$} & \multicolumn{2}{|c|}{$0.0(0.1)$} \\
\hline Faeces & \multicolumn{2}{|c|}{$2.3(0.4)$} & \multicolumn{2}{|c|}{$2.2(0.4)$} & \multicolumn{2}{|c|}{$2.5(0.5)$} & \multicolumn{2}{|c|}{$0.3(0.2)$} \\
\hline Absorption & \multicolumn{2}{|c|}{$1.4(0.4)$} & \multicolumn{2}{|c|}{$1.5(0.4)$} & \multicolumn{2}{|c|}{$1.2(0.5)$} & \multicolumn{2}{|c|}{$-0.3(0.2)$} \\
\hline Absorption (\%) & 37 & $(12)$ & 39 & (11) & 31 & (12) & -8 & $(4)$ \\
\hline \multicolumn{9}{|l|}{ Sodium (mmol/day) } \\
\hline Diet & 160 & $(15)$ & 166 & $(20)$ & 170 & (20) & 5 & $(4)$ \\
\hline Faeces & 179 & $(48)$ & 175 & (39) & 198 & (48) & 23 & (15) \\
\hline Absorption & -19 & $(48)$ & -9 & $(44)$ & -28 & (56) & -18 & (7) \\
\hline Absorption (\%) & -16 & (31) & -16 & (28) & -36 & (37) & -20 & (14) \\
\hline \multicolumn{9}{|c|}{ Potassium (mmol/day) } \\
\hline Diet & 81 & (6) & 81 & (7) & 81 & (7) & 0 & (2) \\
\hline Faeces & 45 & (7) & 42 & (6) & 52 & (8) & 10 & (4) \\
\hline Absorption & 36 & (7) & 41 & (8) & 29 & (9) & -11 & (5) \\
\hline Absorption (\%) & 43 & (9) & 47 & (8) & 33 & (12) & -13 & (5) \\
\hline \multicolumn{9}{|c|}{ Calcium (mmol/day) } \\
\hline Diet & 29 & (4) & 28 & (3) & 31 & (4) & 3 & $(2)$ \\
\hline Faeces & 32 & (3) & 30 & (3) & 33 & (5) & 4 & (2) \\
\hline Absorption & -2 & (3) & -2 & (3) & -2 & (3) & 0 & (1) \\
\hline Absorption (\%) & -16 & (15) & -16 & (19) & -15 & (17) & 1 & (3) \\
\hline \multicolumn{9}{|c|}{ Magnesium (mmol/day) } \\
\hline Diet & 13 & (1) & 14 & (1) & 13 & (1) & 0 & $(0)$ \\
\hline Faeces & 14 & (1) & 13 & (1) & 13 & (1) & 0 & $(0)$ \\
\hline Absorption & 0 & (1) & 1 & (1) & 0 & (1) & 0 & (1) \\
\hline Absorption (\%) & -3 & (9) & 4 & (4) & 2 & (4) & -2 & (4) \\
\hline
\end{tabular}

${ }^{\star}$ Effect is treatment compared with placebo; paired $t$ test, all non significant, $\mathrm{p}>0.05$.

g/day $(27 \%)$ at baseline, 2.6 of $12.3 \mathrm{~g} /$ day $(18 \%)$ after placebo, and 3.6 of $13.4 \mathrm{~g} /$ day $(19 \%)$ after active treatment.

Urinary losses of nitrogen were not affected by active treatment, and the total balance of energy and macronutrients obtained from intestinal absorption and parenteral supplements was not altered (not shown).

INTESTINAL ABSORPTION OF WET WEIGHT, SODIUM, POTASSIUM, CALCIUM, AND MAGNESIUM Absorption of wet weight was 1.4 of $3.7 \mathrm{~kg} /$ day $(37 \%)$ at baseline, 1.5 of $3.7 \mathrm{~kg} /$ day $(39 \%)$ after placebo, and 1.2 of $3.7 \mathrm{~kg} /$ day $(31 \%)$ after active treatment (ns compared with placebo) (table 4). Percentage of absorbed wet weight decreased by 6 (2)\% compared with baseline $(p<0.05)$. Urinary (not shown) and faecal outputs were not changed compared with placebo, and the total balance between enteral and parenteral supplements and faecal and urinary outputs was $0.8-0.9 \mathrm{~kg} /$ day of wet weight and was not significantly affected by active treatment.

Average faecal loss of sodium exceeded intake and mean absorption of sodium was negative (net secretion). A mean of -19 of $160 \mathrm{mmol} /$ day $(-16 \%)$ was absorbed at baseline, -9 of $166 \mathrm{mmol} / \mathrm{day}(-16 \%)$ was absorbed after placebo, and -28 of $170 \mathrm{mmol} /$ day $(-36 \%)$ was absorbed after active treatment (no significant difference from placebo or baseline values). Faecal loss of sodium increased by 20 (5) $\mathrm{mmol} /$ day after active treatment compared with baseline $(\mathrm{p}<0.05)$ but these changes were not significant compared with placebo. Urinary excretion of sodium did not change (not shown).

Absorption of potassium was 36 of $81 \mathrm{mmol} /$ day $(43 \%)$ at baseline, 41 of $81 \mathrm{mmol} /$ day $(47 \%)$ after placebo, and 29 of $81 \mathrm{mmol} /$ day (33\%) after active treatment (not significantly different from baseline or placebo) (table 4). Differences in urinary (not shown) and faecal excretions of potassium after active and placebo treatment were not significant. Absorption of calcium and magnesium was not changed by treatment with combined growth hormone and glutamine (table 4); urinary excretions were also unchanged (not shown). Oral intake of energy, macronutrients, wet weight, sodium, potassium, calcium, and magnesium were similar for the treatment, baseline, and placebo periods (tables 3, 4).

INFLUENCE OF A COLON

Absorption of energy and fat was not significantly different in patients with and without a colon, but a preserved colon tended to be associated with increased absorption of carbohydrates (mean with a colon, $80 \%$; no colon, $61 \% ; \mathrm{p}=0.06$ ), wet weight (with a colon, $56 \%$; no colon, $18 \% ; \mathrm{p}=0.11$ ), and sodium (with a colon, $54 \%$; no colon, $-85 \%$; $\mathrm{p}=0.007$ ) (table 5). The effects of treatment (treatment minus baseline) were not significantly different between patients with and without a colon (table 5). Baseline concentrations of IGF-1 and the increase in concentration during treatment with growth hormone did not differ between patients with and without a colon (table 5).

\section{WEIGHT}

Active treatment increased weight by 1.03 $(0.34) \mathrm{kg}(\mathrm{p}<0.05)$ compared with weight at baseline $(58.90(3.54) \mathrm{kg})$ and by $0.65(0.30)$ $\mathrm{kg}$ (not significant) compared with placebo.

SERUM IGF-1

At baseline, mean serum IGF-1 level in the eight patients was $159 \mathrm{ng} / \mathrm{ml}$ (range 93-254) (table 5). Treatment with growth hormone increased IGF-1 (mean after one, two, and three weeks $489 \mathrm{ng} / \mathrm{ml}$ (range 291-688), 569 $\mathrm{ng} / \mathrm{ml}$ (306-967), and $591 \mathrm{ng} / \mathrm{ml}$ (287-1007), respectively) compared with during the placebo period (mean after one, two, and three 
Table 5 Baseline values and effect of growth hormone and glutamine (treatment minus baseline) on intestinal absorption and serum insulin-like growth factor 1 (IGF-1) in individual patients with and without a preserved colon

\begin{tabular}{|c|c|c|c|c|c|c|c|c|c|c|c|c|c|}
\hline \multirow{3}{*}{$\begin{array}{l}\text { Patient } \\
\text { No }\end{array}$} & \multirow[b]{3}{*}{ Colon } & & & \multicolumn{10}{|c|}{ Intestinal absorption (\% of oral intake) } \\
\hline & & \multicolumn{2}{|c|}{$I G F(n g / m l)$} & \multicolumn{2}{|l|}{ Energy } & \multicolumn{2}{|c|}{ Carbohydrates } & \multicolumn{2}{|l|}{ Fat } & \multicolumn{2}{|c|}{ Wet weight } & \multicolumn{2}{|l|}{ Sodium } \\
\hline & & Baseline & Effect ${ }^{\star}$ & Baseline & Effect & Baseline & Effect & Baseline & Effect & Baseline & Effect & Baseline & Effect \\
\hline 1 & Yes & 138 & +331 & 46 & +1.8 & 81 & +3.0 & -7 & +4.1 & 45 & -15.1 & 62 & -7.2 \\
\hline 2 & Yes & 99 & +196 & 51 & +1.5 & 81 & +1.0 & 27 & +3.6 & 55 & +1.3 & 76 & -6.7 \\
\hline 3 & Yes & 189 & +418 & 47 & -12.2 & 75 & -9.1 & 44 & -38.0 & 47 & -1.1 & 28 & +16.8 \\
\hline 4 & Yes & 93 & +344 & 67 & -0.5 & 84 & +0.2 & 35 & -3.5 & 76 & -10.6 & 49 & -14.1 \\
\hline 5 & No & 134 & +478 & 33 & +2.0 & 60 & +0.9 & -9 & +22.1 & 0 & -13.6 & -125 & -32.2 \\
\hline 6 & No & 205 & +462 & 64 & -5.0 & 79 & -2.4 & 40 & -8.3 & 39 & -5.0 & -72 & -107.1 \\
\hline 7 & No & 254 & +633 & 42 & +4.8 & 65 & +0.9 & 26 & -3.9 & 59 & -0.3 & 2 & -16.6 \\
\hline 8 & No & 159 & +250 & 17 & +5.4 & 41 & +8.0 & 1 & +6.5 & -26 & +2.8 & -145 & +3.2 \\
\hline Mean & Yes & 130 & +322 & 53 & -2.4 & 80 & -1.2 & 25 & -8.5 & 56 & -6.4 & 54 & -2.8 \\
\hline Mean & No & 188 & +456 & 39 & +1.8 & 61 & +1.9 & 15 & 4.1 & 18 & -4.0 & -85 & -38.2 \\
\hline $\mathrm{p}$ & & 0.14 & 0.19 & 0.26 & 0.35 & 0.06 & 0.41 & 0.54 & 0.34 & 0.11 & 0.67 & 0.007 & 0.21 \\
\hline
\end{tabular}

${ }^{\star}$ Effect on IGF, mean IGF (ng/ml) after one, two, and three weeks of active treatment minus IGF at baseline.

weeks $179 \mathrm{ng} / \mathrm{ml}$ (range 83-302), $158 \mathrm{ng} / \mathrm{ml}$ (65-216), and $154 \mathrm{ng} / \mathrm{ml}$ (65-240), respectively). On average, IGF-1 was $389 \mathrm{ng} / \mathrm{ml}$ (range 196-633) (table 5) above baseline values and $384 \mathrm{ng} / \mathrm{ml}$ (range 224-635) above placebo.

\section{ADVERSE EFFECTS}

All patients had side effects that are known to occur during treatment with high doses of growth hormone. Complaints were registered continuously and all patients associated their side effects with one of the treatment arms only. When the code was subsequently broken, $100 \%$ correlation between active treatment and reported side effects was found (that is, in retrospect all eight patients were able to identify when they received active treatment). All patients gained weight while on active treatment and all had sensations of fluid retention. Peripheral oedema requiring reduction in parenteral supplements was observed in six patients. Growth hormone was reduced in four patients. Five needed oral treatment with frusemide at maximum doses of 20, 40, 120, 160 , and $320 \mathrm{mg} /$ day, respectively. Oedema disappeared in all cases within one week after discontinuation of active treatment. Six patients required analgesics because they developed severe hand pain while receiving active treatment. Three patients needed opiates (buprenorphine, Ketogan R, and morphine). The pain disappeared gradually over $2-3$ weeks in five patients but one patient required bilateral surgery for persistent carpal tunnel syndrome 4-5 months after discontinuation of treatment. The single male participant developed gynaecomastia and subsequently underwent a lumpectomy with removal of a benign tumour. There were no significant changes in blood counts, blood glucose, serum electrolytes, or liver and renal tests during the study period. All eight patients completed the two phases of 28 days of active or placebo treatment despite the side effects.

\section{Discussion}

Studies in animals have indicated that growth hormone combined with glutamine improves intestinal growth, function, and adaptation. ${ }^{1}{ }^{2} 11$ The studies of Byrne and colleagues ${ }^{4-6}$ indicate that the same may apply to humans with intes- tinal failure caused by short bowel syndrome. However, they combined growth hormone and glutamine with a modified $61 \%$ high carbohydrate $18 \%$ low fat diet, and oral fluids were administered as solutions of isotonic glucosesodium (Gatorade R). ${ }^{5}$ Patients were treated for 28 days with intravenous growth hormone $0.14 \mathrm{mg} / \mathrm{kg} /$ day and intravenous glutamine $0.42 \mathrm{~g} / \mathrm{kg} /$ day and/or enteral glutamine $0.63 \mathrm{~g} / \mathrm{kg} /$ day. Balance studies were performed in eight patients. Baseline dietary intake was $2692 \mathrm{kcal} /$ day, and $1618 \mathrm{kcal} /$ day $(6.8 \mathrm{MJ} /$ day, $60 \%$ ) were absorbed. Intake and absorption were 2367 and $1759 \mathrm{kcal} /$ day $(74 \%)$, respectively, after four weeks of treatment, in percentage a highly significant improvement $(\mathrm{p}<0.003)$ but in absolute amounts an increase of only $141 \mathrm{kcal} /$ day. Absorption of carbohydrates (from $60 \%$ to $82 \%$ ) and protein (from $49 \%$ to $63 \%$ ) increased whereas absorption of fat was unchanged $(61 \%$ and $60 \%)$. Wet weight absorption increased from $1.7 \mathrm{~kg} /$ day (51\%) to $2.4 \mathrm{~kg} /$ day $(68 \%)$, and absorption of sodium increased from $74 \mathrm{mmol} /$ day $(49 \%)$ to $113 \mathrm{mmol} /$ day $(70 \%)$.

At baseline their patients absorbed more energy $(6.8 \mathrm{MJ} /$ day, $60 \%)$ and wet weight $(1.7$ $\mathrm{kg} /$ day, $51 \%$ ) compared with our patients $(4.5$ $\mathrm{MJ} /$ day, $46 \%$ (table 3 ) and $1.4 \mathrm{~kg} /$ day, $37 \%$ (table 4), respectively). Therefore, one might expect a proportion of their patients to adapt and become independent of parenteral nutrition as was reported to occur in $50 \% .^{4}$ In our experience, short bowel patients adapt to a life without parenteral nutrition if both energy and wet weight absorption exceed $4.9 \mathrm{MJ} /$ day and $1.4 \mathrm{~kg} /$ day, respectively. ${ }^{12}$

Studies have indicated that high carbohydrate diets are better absorbed in short bowel patients compared with diets more rich in fat. A change from a $20 \%$ low carbohydrate $/ 60 \%$ high fat diet to an isocaloric $60 \%$ high carbohydrate $/ 20 \%$ low fat diet improved energy uptake by $2 \mathrm{MJ} /$ day in short bowel patients with a preserved colon. ${ }^{3}$ Malabsorption of carbohydrates was less in patients with a colon in comparison with patients who had equally short lengths of small bowels but no colon, ${ }^{13}$ partly because carbohydrates malabsorbed in the small bowel are fermented by the colonic bacteria to short chain fatty acids which are absorbed and metabolised. The effect of a high 
carbohydrate low fat diet seems less evident in patients without a colon and did not reach significance in studies involving only a few patients. ${ }^{13-15}$ In the present study mean absorption of energy was $46-48 \%$, distributed over absorption of carbohydrates of $70-71 \%$ and a much lower absorption of fat of 15-20\% (table 3). Consequently, if we had included a modified high carbohydrate/low fat diet, it is likely that we would have found an increase in absorption of dietary energy.

The randomised controlled study by Scolapio and colleagues ${ }^{7}$ in eight short bowel patients treated for 21 days with high dose growth hormone and glutamine and no change in diet (continuous $60 \%$ high carbohydrate $/ 20 \%$ low fat diet) found no difference in stool volumes, absorption of fat and xylose, and no changes in the morphometry of the small bowel mucosa. A modest increased absorption of sodium and potassium during the end of active treatment was recorded, and body weight increased transiently. We found that treatment tended to decrease wet weight absorption and increase faecal excretion of sodium and potassium (table $4)$, which reached significance $(p<0.05)$ compared with baseline values. These findings were contrasted by clinical findings of oedema, increased weight, need for diuretics, and reduction in parenteral saline during treatment. However, symptoms disappeared within a week after active treatment was stopped, and our patients were probably in the process of excreting water and sodium accumulated during the treatment at the time we performed the balance studies.

The two main differences between Scolapio's study and ours was that our patients maintained their usual dietary ratios of carbohydrate and fat (on average $46 \%$ carbohydrate, table 2) rather than being on a high carbohydrate diet, and that intestinal function was measured five days after treatment was stopped instead of on the last days before treatment was terminated.

Our study supports the results of Scolapio et al that in patients on a fixed diet, habitual or rich in carbohydrates, combined growth hormone and glutamine have no effect on absorption of fat or nitrogen. In addition, we found no improvement in absorption of energy, carbohydrates, calcium, or magnesium (tables 3, 4). Treatment with high dose growth hormone and glutamine may increase absorption of water and sodium but the effect seems to be transient with no long term improvement in gut function when treatment is discontinued.

It has been argued that colonic continuity could be important for the efficiency of growth hormone and glutamine in the short bowel syndrome. ${ }^{6}$ In the study of Byrne et al, all patients had a colon while in the study of Scolapio et al, only two patients had a colon. Table 5 shows baseline values and effects of treatment in individual patients, four with a colon and four without. Differences in the effect of treatment between patients with and without a colon were not detectable. Patients with a colon tended to have better baseline absorption of carbohydrates, water, and sodium as expected.
To our knowledge no studies, other than those mentioned, have evaluated the effect of high dose growth hormone and glutamine in short bowel syndrome. Ten short bowel patients were treated with a sixfold lower dose of growth hormone $(0.024 \mathrm{mg} / \mathrm{kg} /$ day $)$ as monotherapy for eight weeks in a Swedish study. ${ }^{16}$ No effect on intestinal absorption of energy, nitrogen, water, sodium, potassium, calcium, or magnesium was found. In contrast, a recent randomised controlled study from Paris, presented only as an abstract, ${ }^{17}$ reported that an intermediary dose of growth hormone $(0.05 \mathrm{mg} / \mathrm{kg} /$ day for three weeks) improved absorption of energy, carbohydrates, fat, and nitrogen in 12 short bowel patients on a non-restricted diet. Body weight increased by $2.0 \mathrm{~kg}$ and side effects were not encountered.

In conclusion, we found no improvement in intestinal absorption of energy, macronutrients, wet weight, sodium, potassium, magnesium, or calcium five days after discontinuation of 28 days of treatment with high dose growth hormone combined with oral and parenteral glutamine in short bowel patients maintained on their usual diet compared with pretreatment baseline status or placebo treatment. High dose growth hormone and glutamine may increase intestinal water and sodium absorption but the results of this study suggest that the effects are not sustained beyond the period of treatment. Continuous treatment with high dose growth hormone would increase the costs of HPN approximately four times, and unpleasant adverse effects seem to accumulate in a number of patients.

The technical assistance of Birthe Stenbaek Hansen and Jette Christiansen is greatly appreciated. Growth hormone and placebo were kindly provided by Novo Nordisk A/S, Bagsværd, Denmark.

1 Guarino A, Canani RB, Iafusco M, Casola A, Russo R, Rubino A. In vivo and in vitro effects of human growth hormone on rat intestine ion transport. Pediatr Res hormone on rat

2 Gardemann A, Watanabe Y, Grosse V, Hesse S, Jungermann $\mathrm{K}$. Increase in intestinal glucose absorption and hepatic glucose uptake elicited by luminal but not vascular glutamine in the jointly perfused small intestine and liver in the rat. Biochem f 1992;283:759-65.

3 Nordgaard I, Hansen BS, Mortensen PB. Colon as a digestive organ in patients with short bowel. Lancet 1994;343: 373-6.

4 Byrne TA, Morissey TB, Nattakom TV, Ziegler TR, Wilmore DW. Growth hormone, glutamine and a modified diet enhance nutritient absorption in patients with severe short bowel syndrome. FPEN F Parenter Enteral Nutr 1995;
19:296-302.

Byrne TA, Persinger RL, Young LS, Ziegler TR, Wilmore DW. A new treatment for patients with short-bowel syndrome. Growth hormone, glutamine and a modified diet. Ann Surg 1995;222:243-55.

6 Byrne T, Wilmore D. Does growth hormone and glutamine Byrne T, Wilmore D. Does growth hormone and glutamine
enhance bowel absorption? Gastroenterology 1998;114: enhance $1110-1$.

7 Scolapio JS, Camillieri M, Fleming CR, et al. Effect of growth hormone, glutamine, and diet on adaptation in hort-bowel syndrome: A randomised, controlled study. Gastroenterology 1997;113:1074-81

8 Cummings JH, James WP, Wiggins HS. Role of the colon in ileal-resection diarrhoea. Lancet 1973;1:344-7.

9 Levnedsmiddelstyrelsen (National Food Agency of Denmark). Dankost version 1.3b. Storkøkken Center, Herlev, Denmark: Levnedsmiddelstyrelsen, 1989.

10 Jeppesen PB, Mortensen PB. The influence of a preserved colon on the absorption of medium chain fat in patients with small bowel resection. Gut 1998;43:478-83.

11 Souba W, Klimberg S, Plumley D, Salloum R, Flynn T. The role of glutamine in maintaining a healthy gut and supporting the metabolic response to injury and infection. F Surg Res 1990;48:383-91.

12 Jeppesen PB, Mortensen PB. Intestinal failure defined by measurements of energy and wet weight absorption. Gut 2000;46:701-6. 
13 Nordgaard I, Hansen BS, Mortensen PB. Importance of colonic support for energy absorption as small-bowel colonic support for energy absorption as small-bowel

14 Ameen VZ, Powell GK, Jones LA Quantitation of faecal carbohydrate excretion in patients with short bowel syndrome. Gastroenterology 1987;92:493-500.

15 Royall D, Thomas RPDT, Wolever TMS, Jeejeebhoy K. Evidence for colonic conservation of malabsorbed carbohydrate in short bowel syndrome. Am f Gastroenterol 1992;87:751-6.
16 Ellegaard L, Bosaeus I, Nordgren S, Bengtsson BA. Low-dose recombinant human growth hormone increases body weight and lean body mass in patients with short bowel syndrome. Ann Surg 1997;225:88-96.

17 Souberbielle JC, Postel-Vinay MC, Thuillier F, Gobert JG, Messing B. Growth hormone benefit in very short bowel patients: a randomized controlled trial. Clin Nutr 1999;18: (suppl 1) 13. 